\title{
Práticas de Saber-Poder entre Pobreza e Negligência que se configu- ram na Institucionalização da Infância
}

\author{
Practices of Power-Knowledge between Poverty and Neglect that are Formed in Childhood Institu- \\ tionalization
}

Thiago Rosa Assis de Oliveira*, Roberta Barbosa da Silva

Como citar esse artigo. de Oliveira, TRA; da Silva, RB. Práticas de SaberPoder entre Pobreza e Negligência que se configuram na Institucionalização da Infância. Revista Mosaico 2019 Jul/ Dez.; 10 (2): SUPLEMENTO 96-104.

\begin{abstract}
Resumo
O presente trabalho objetiva problematizar o conceito de negligência no âmbito familiar, jurídico e social como motivo para o acolhimento institucional de crianças e adolescentes no Estado do Rio de Janeiro, a partir de dados divulgados pelo Ministério Público do Estado do Rio de Janeiro no Módulo Criança e Adolescente - MCA. Os dados analisados apresentam os índices de acolhimento institucional realístico em todo o Estado, onde ficou constatado que desde sua primeira edição em 2008 até o ano de 2017, a negligência é apontada como a maior causadora dos acolhimentos, além, de ser apresentada como a maior das violações de direitos. Apresentamos um breve percurso legislativo do código de menores até o Estatuto da Criança e do Adolescente, bem como, os desafios atuais desta nova legislação. Para contextualizar estas problematizações recorremos ao filósofo Michel Foucault.

Palavras-Chave: Negligência, Pobreza, Institucionalização.
\end{abstract}

\section{Introdução}

O Estatuto da Criança e do Adolescente - ECA (BRASIL, 1990), estabelecido na lei $\mathrm{n}^{\mathrm{o}} 8.069$ de 13 de julho de 1990, dispõe sobre a proteção integral à criança e ao adolescente, em seu artigo $3^{\circ}$ afirmando que as crianças e os adolescentes gozam de todos os direitos fundamentais inerentes à pessoa humana, com o objetivo de assegurar o desenvolvimento físico, mental, moral, espiritual e social, bem como, a liberdade e a dignidade. $\mathrm{E}$, no artigo $5^{\circ}$ a lei afirma que:

Art. 50: Nenhuma criança ou adolescente será objeto de qualquer forma de negligência, discriminação, exploração, violência, crueldade e opressão, punido na forma da lei qualquer atentado, por ação ou omissão, aos seus direitos fundamentais (BRASIL, 1990).

Dentro do cenário jurídico, médico, assistencial, educacional etc., as violações de direitos vão se estabelecendo de diversas formas, entre elas, a negligência, citada no artigo $5^{\circ}$ do ECA, e que tomaremos como campo de pesquisa neste trabalho. Esta aparece como motivo principal dos acolhimentos institucionais de crianças e adolescentes no Estado do Rio de Janeiro, de acordo com os dados divulgados pelo Ministério Público do Estado do Rio de Janeiro no Módulo Criança

Afiliação dos autores:Universidade de Vassouras/Vassouras/RJ/Brasil 
e Adolescente - MCA. Este módulo nasce como uma iniciativa do Ministério Público do Estado do Rio de Janeiro com objetivo de criar um cadastro online contendo dados dos programas de acolhimento de cada criança ou adolescente acolhido no Estado visando facilitar ações de reintegração familiar e social.

Com análise nos dados divulgados no MCA e na literatura, pretendemos mostrar a amplitude do conceito de negligência que pode conduzir a uma utilização indevida, e que esta, tem sido fomentada como substituta da pobreza para os acolhimentos, quando, na verdade, é preciso avaliar vários aspectos sociais antes de definir a negligência como fator principal. Problematizaremos o conceito de negligência com ressalva no artigo $5^{\circ}$ da lei $\mathrm{N}^{\circ}$ 8.096/90 - Estatuto da Criança e do Adolescente/ ECA (BRASIL, 1990) e questionaremos se as práticas que subsidiavam ações segregatórias e excludentes moduladas no Decreto $\mathrm{n}^{\circ} 17943-\mathrm{A}$, de 12 de outubro de 1927 (Código de menores) onde vigorava a situação de irregularidade e delinquência sobre as crianças e adolescentes em situação de vulnerabilidade social ainda se fazem presentes em meio à nova legislação.

Trazer essa questão para discussão é importante, uma vez que a atuação do poder judiciário no Brasil, especialmente nas Varas da Família e da Infância, e em diversos órgãos de assistência familiar e garantia de direitos, tem se pautado no conceito de negligência para embasar suas decisões e justificar algumas de suas ações.

Como base para essa discussão, foram utilizados dados dos censos do MCA que apresentam os índices de acolhimento institucional realísticos em todo o Estado do Rio de Janeiro, destacando os motivos que ocasionaram a decisão; autores e referências de literatura que problematizam as práticas do psicólogo nesse cenário, bem como, a utilização do conceito de negligência. Já o Estatuto da Criança e do Adolescente - Lei no ${ }^{\circ} 8.069 / 90$ é uma nova legislação fruto da luta pela redemocratização que busca efetivar uma visão igualitária para a garantia de direitos fundamentais à condição humana, a partir, da proteção integral, que veio substituir o Código de Menores instituído em 1927 onde vigorava a situação de irregularidade e deliquência. No demais trazemos a contextualização pela revisão de literatura que será entrelaçada ao discurso filosófico de Michel Foucault.

\section{Trajeto legislativo: Do código de menores ao estatuto da criança e do adolescente}

$\mathrm{O}$ pensamento positivista que emerge na França no começo do século XIX, se associa a teoria evolucionista do ser humano desenvolvida por Darwin e encontra no poder político da burguesia na época, a força necessária para tratar as relações sociais e reforçar a preocupação com a coesão social e o bom funcionamento da ordem. Neste momento, surgem leis que visam definir critérios de normalidade, regularidade, funcionamento e ordem para que os ideais de uma classe dominante fossem garantidos e preservados com sucesso e sem interferências. De forma "natural", foram sendo construídos estilos de vida ditos como modelos a serem seguidos - logicamente que estes eram os vividos pelas famílias ricas - e, estilos de vida ditos como irregulares e desviantes - todos os demais que não se adequasse ao modelo anterior, que constituíam as famílias pobres. O poder político hegemônico produz a determinação de classes sociais e ao mesmo tempo se exima de sua responsabilidade sobre elas. A partir do pensamento positivista, cada indivíduo passa a ter a necessidade de adaptar e adequar-se as ordens estabelecidas. Neste momento temos a formulação das leis que ficaram conhecidas como "leis menoristas" no Brasil (SHEINVAR, 2002).

\begin{abstract}
Tal a lógica do pensamento jurídico, a partir da qual também são formuladas no Brasil, desde o século XIX, as leis relativas à criança e ao adolescente. Estruturadas a partir do critério etário, instrumentalizado pelos adjetivos "maior" e "menor", tornaram-se conceitos definidores das relações sociais (SHEINVAR, 2002, p. 3).
\end{abstract}

Em 1927 foi sancionado o Código de Menores Mello Matos que ao longo de sua vigência na figura do juiz e com discurso de proteção, assistência e prevenção, tinha por finalidade o controle das virtualidades dos filhos das classes inferiores; adotava a visão de delinquência, além de, critérios para enquadramentos na lei e aplicação de medidas "educativas e não punitivas". Tais medidas "educativas" eram destinadas ao aprendizado de um ofício como: trabalho em casas de família, fábricas, fazendas e até mesmo as forças militares. Assim, o destino de cada uma daquelas crianças e adolescentes era quase sempre o trabalho forçado e cerceamento da infância. Desta maneira, a assistência pública passou a atuar como uma extensão do sistema, uma auxiliadora da justiça, e com isto, a prática de recolhimento de crianças e adolescentes pelas ruas aumentou desenfreadamente, criando pilhas de processos sob as mesas dos juízes de menores (ARANTES, 2015).

Já em 1979 temos uma nova edição da lei anterior que trouxe a Doutrina da Proteção ao Menor em Situação Irregular, mudando assim a visão de delinquência adotada anteriormente e, adotou instrumentos punitivos, colocando o "menor" visto como um criminoso em potencial e doente social.

Um marco importante na transição deste cenário vivido até então, para se chegar aos tempos atuais, foi o processo de democratização do país, que através de movimentos sociais, buscava o fim do regime ditatorial. Neste mesmo processo, a área da infância e da juventude começou a ser questionada e formularam- 
se outras maneiras de pensar e métodos de atuação diferentes. Assim, entra em vigor a lei no 8.069 em 13 de julho de 1990, conhecida como Estatuto da Criança e do Adolescente - ECA. Esta propõe uma cisão total do modelo menorista e traz a ideia de proteção integral, afirmando que crianças e adolescentes são sujeitos de direitos.

Nascimento (2011) afirma que com a emergência do ECA, a família pobre ganhou um novo status passando a ser chamada de família negligente, o que justificaria a intervenção do Estado e a continuidade da prática de retirar crianças e adolescentes de suas famílias. "Não se retira mais por pobreza, mas, se retira por negligência. E, são os pobres os considerados negligentes" (NASCIMENTO, 2011).

\section{Reflexões sobre a implantação do Estatuto da Criança e do Adolescente: Do código de menores a alguns enfrentamentos atuais}

\begin{abstract}
Apesar do ECA propor uma ruptura com o modelo menorista presente na legislação precedente, o que verificamos após sua promulgação é a permanência de forças que criminalizam e punem as famílias, as crianças e os adolescentes pobres. Outras nomenclaturas reproduzem antigos modelos e continuam a construir formas cada vez mais amplas e sofisticadas de controle da vida. É importante salientar que não estamos falando em continuidades ou em mutações que a infância, a adolescência e a família pobre sofreram ao longo dos tempos. $\mathrm{O}$ que buscamos afirmar é o caráter processual dos agenciamentos, das relações de força e dos dispositivos de poder que as instituíram como tal (SILVA, 2014, p. 43).
\end{abstract}

O trecho acima afirma que o ECA visava novas práticas ao "romper" com as que existiam nos códigos de menores, porém, se perdurou a essência criminalizante e excludente que regiam as famílias mais pobres. O que diferencia tais práticas é a assistência caritativa com que a legislação anterior assistia às crianças pobres com o discurso de corrigi-las e regenerá-las como se fossem condenados.

Arantes (2015, p. 30-31) afirma: "consideramos este o maior desafio que temos pela frente: o de entendermos o caráter ético, jurídico, político e social da Proteção Integral". Tal desafio exigirá de todos nós, e em especial do psicólogo, uma análise de nossas implicações, paraquepossamosfavoreceroprotagonismo de crianças e adolescentes, e não comportamentos meramente adaptativos. Exigirá, igualmente, de todos os operadores do Sistema de Garantias de Direitos e da Rede de Atendimento, o esforço de um olhar novo, para que os direitos humanos sejam realmente considerados indivisíveis e interdependentes, evitando-se ações fragmentadas e pontuais.

\section{$O$ conceito do termo negligência}

No livro Psicologia Jurídica no Brasil, Hebe Signorini Gonçalves $(2015$, p. 307) afirma que: "o termo negligência designa as omissões dos pais ou de outros responsáveis - inclusive institucional - pela criança e pelo adolescente quando deixam de prover as necessidades básicas para seu desenvolvimento físico, emocional e social". Partindo deste princípio não seria uma pessoa negligente o/a cuidador (a) que provê a alimentação diária e necessária ao bebê, seu banho no devido horário, a dosagem correta do remédio e a consulta médica no prazo determinado ou mesmo quando assim se faz necessário diante de um quadro de emergência inesperado, entre outros cuidados considerados vitais. Tudo aquilo que foge e destoa do que consideramos padrão perante a sociedade é considerado negligência e está passível às sanções penais aplicáveis na vasta gama de leis existentes, como no Estatuto da Criança e do Adolescente (ECA). A autora também levanta como questão o saber diferenciar entre negligência e pobreza. Segundo ela: "a negligência se aproxima da pobreza e da desigualdade social" (GONÇALVES, 2015).

Phebo e Ojeda (1996) afirmam ser muito comum interpretar erroneamente a falta de recursos materiais com a negligência em lugares onde ocorre a pobreza extrema. É preciso pensar em todo o contexto familiar e social para que talvez se consiga chegar mais próximo possível da linha de separação entre a pobreza e a negligência. Diante de uma realidade social, onde a família não possui recursos financeiros que possam custear todos os itens necessários para o bom desenvolvimento físico e emocional de seus filhos não podemos classificar como negligência, pois, a organização familiar está comprometida como um todo, ou seja, tal violência acomete não apenas aos filhos, como também aos pais e os demais membros da família. Mas, se temos uma situação onde apenas os filhos desta família são privados de acesso a cuidados básicos e, de materiais fundamentais para si, podemos então, tratar como violência. Os autores exemplificam a negligência seletiva que ocorre em lugares onde o índice de mortalidade de bebês recém-nascido é muito alto devido às condições de vida insalubres e a falta de acesso a políticas públicas, neles tal condição não se dá por falta de amor e cuidado pela mãe, e sim, por um mecanismo de defesa diante da provável morte de seu filho.

A negligência é vista como um desvio de algo rotulado com o ideal de proteção, um modelo que se deve seguir e que todo comportamento que foge desta regra passa a ser classificado como patológico e causador de desequilíbrio na ordem social (NASCIMENTO, 2011).

Se a negligência é vista como uma infração, os pais 
ou os responsáveis legais são os "infratores" passíveis de serem julgados culpados ou inocentes perante o tribunal da judicialização - termo do qual o conceito será discutido ao longo do texto. Como resultado da culpabilização temos a aplicação de medidas protetivas que pode ser um acolhimento institucional ou mesmo a destituição do poder familiar no caso mais grave, conforme a legislação. Outra inquietude que surge é se tal realidade diante da aplicação de uma ou ambas as medidas protetivas possíveis se faz mais danosa para os pais/responsáveis agressores, ou, para o filho que precisará dar conta de mais esta situação e seus agravantes.

\section{Os dados estatísticos}

Ao longo de suas edições, o MCA constatou em seus censos que de fato a negligência se configurou, como o principal motivo dos acolhimentos realizados. Com o objetivo de sintetizar as informações não serão apresentados todos os censos publicados até o presente momento, apresentando apenas tabelas publicadas no $1^{\circ}$ (2008) e $20^{\circ}$ censo (2017) e gráfico do serviço disque 100 da Secretaria de Direitos Humanos.

Dentre os motivos para o acolhimento o $1^{\circ}$ censo já trazia a negligência como responsável de 14,34\%

Tabela $1.1^{\circ}$ Censo MCA

\begin{tabular}{|c|c|c|c|c|}
\hline \multicolumn{5}{|c|}{ Motivo de abrigamento } \\
\hline Motivo & $n^{\circ}$ de c/a & $\%$ & feminino & masculino \\
\hline Negligência & 535 & 14,34 & 251 & 284 \\
\hline Carência de recursos materiais da familia ou responsáveis & 477 & 12,78 & 266 & 211 \\
\hline Não informado & 477 & 12,78 & 238 & 239 \\
\hline Abandono pelos pais ou responsáveis & 436 & 11,68 & 196 & 240 \\
\hline Outros & 405 & 10,85 & 174 & 231 \\
\hline Violência doméstica (maus tratos físicos ou psicologicos) & 325 & 8,71 & 161 & 164 \\
\hline Situação de rua & 221 & 5,92 & 94 & 127 \\
\hline Pais ou responsáveis dependentes químicos ou alcoolistas & 183 & 4,90 & 86 & 97 \\
\hline Abuso sexual / suspeita de abuso sexual & 114 & 3,05 & 93 & 21 \\
\hline Orfandade & 108 & 2,89 & 49 & 59 \\
\hline Risco de vida na comunidade & 101 & 2,71 & 36 & 65 \\
\hline Em razăo de sua conduta & 77 & 2,06 & 41 & 36 \\
\hline Falta de creche ou escola em horário integral & 56 & 1,50 & 30 & 26 \\
\hline Uso abusivo de drogas ou álcool & 23 & 0,62 & 11 & 12 \\
\hline Exploração sexual para fins de prostituiçăo infanto juvenil & 3 & 0,08 & 1 & 2 \\
\hline Prostituição dos pais & 3 & 0,08 & 2 & 1 \\
\hline Transferências & 188 & 5,04 & 73 & 115 \\
\hline Total & 3.732 & 100,00 & 1.802 & 1.930 \\
\hline
\end{tabular}

(conforme tabela 1), o que corresponde ao número de 535 crianças e/ou adolescentes na época. O que chama a atenção é o segundo tópico onde intitula a carência de recursos materiais da família ou responsáveis como motivo para o acolhimento de 477 delas e em seguida um motivo não declarado para o mesmo número de acolhidos.

No que diz respeito ao segundo tópico da tabela acima, notamos claramente que a pobreza vem se constituindo como motivo para realização do acolhimento institucional ainda que o estatuto (ECA) viesse condenando tal prática que vigorava no Código de Menores. Vejamos o que diz no artigo 23 do ECA: $A$ falta ou a carência de recursos materiais não constitui motivo suficiente para a perda ou a suspensão do pátrio poder familiar (Expressão substituída pela Lei $n^{o}$ 12.010, de 2009). Andrade (2016) do Ministério Público de Pernambuco ao comentar o artigo citado acima afirma que:

Dos maiores avanços trazidos pelo bem-vindo Estatuto da Criança e do Adolescente, a regra do art. 23 enterrou de vez nos escombros da recente história deste País, o entulho autoritário representado pela combinação do art. 45, I, com o art. $2^{\circ}$, I, "b", do revogado Código de Menores- Lei 6.697, de 10.10.79 [...] (ANDRADE, 2016).

Realizando uma análise com base nos dados do MCA apresentados na tabela 1 e, refletindo nas alegações 
feitas pelo autor acima, fica claro que o mesmo "entulho autoritário representado pela combinação do art. 45 , I, com o art. $2^{\circ}$, I, "b", do revogado Código de Menores Lei 6.697, de 10.10.79" não está devidamente enterrado ao se fazer presente nos discursos que motivaram os acolhimentos institucionais de centenas de crianças em pleno século XXI.

Ao analisarmos a negligência e suas implicações diante do acolhimento podemos também abarcar o abandono pelos pais/responsáveis - conforme o $4^{\circ}$ tópico da tabela anterior - como uma das mais fortes e cruéis formas de negligenciar os cuidados perante seus filhos. $\mathrm{O}$ ato de abandonar é deixar à própria sorte, desamparar, tendo esta, condições físicas e psicológicas de se cuidar ou não.

$\mathrm{Na}$ tabela seguinte, notamos que no $20^{\circ}$ Censo, a negligência se ocupou de 530 do total de acolhidos, em seguida a situação de rua com 163 dos casos precedendo o abandono pelos pais ou responsáveis pela criança ou adolescente com 156 e os conflitos no ambiente familiar com 147.

Apontamos aqui duas questões principais, e para isto, retornamos ao que foi afirmado anteriormente: em primeiro lugar, algo que nos parece extremamente

Tabela 2. $20^{\circ}$ Censo MCA

Motivo de acolhimento.

\begin{tabular}{|c|c|c|c|c|}
\hline Motivo & número de cla & $\%$ & feminino & masculino \\
\hline Negligência & 530 & 31,07 & 215 & 315 \\
\hline Situação de Rua & 163 & 9,55 & 59 & 104 \\
\hline Abandono pelos pais ou responsáveis & 156 & 9,14 & 74 & 82 \\
\hline Conflitos no ambiente familiar & 147 & 8,62 & 78 & 69 \\
\hline $\begin{array}{l}\text { Devolução por tentativa de colocação familiar mal } \\
\text { sucedida }\end{array}$ & 141 & 8,26 & 72 & 69 \\
\hline $\begin{array}{l}\text { Pais ou responsáveis dependentes quimicos ou } \\
\text { alcoolistas }\end{array}$ & 106 & 6,21 & 50 & 56 \\
\hline $\begin{array}{l}\text { Abusos fisicos ou psicológicos contra a criança ou } \\
\text { adolescente }\end{array}$ & 102 & 5,98 & 52 & 50 \\
\hline Em razão de sua conduta & 72 & 4,22 & 34 & 38 \\
\hline Abuso sexual / Suspeita de abuso sexual & 69 & 4,04 & 49 & 20 \\
\hline $\begin{array}{l}\text { Carência de recursos materiais da familia ou } \\
\text { responsáveis }\end{array}$ & 45 & 2,64 & 22 & 23 \\
\hline Risco de vida na comunidade & 34 & 1,99 & 9 & 25 \\
\hline $\begin{array}{l}\text { Responsável impossibilitado de cuidar por motivo } \\
\text { de doença }\end{array}$ & 33 & 1,93 & 13 & 20 \\
\hline Transferência de Familia Acolhedora & 33 & 1,93 & 15 & 18 \\
\hline $\begin{array}{l}\text { Genitor(es) menor(es) de } 18 \text { anos abrigado(s) } \\
\text { com o filho }\end{array}$ & 26 & 1,52 & 14 & 12 \\
\hline Uso abusivo de drogas ou álcool & 14 & 0,82 & 1 & 13 \\
\hline $\begin{array}{l}\text { Responsável cumprindo pena privativa de } \\
\text { liberdade }\end{array}$ & 12 & 0,70 & 6 & 6 \\
\hline Falta de creche ou escola em horário integral & 10 & 0,59 & 3 & 7 \\
\hline Orfandade & 10 & 0,59 & 4 & 6 \\
\hline $\begin{array}{l}\text { Genitor(es) maior(es) de } 18 \text { anos abrigado(s) com } \\
\text { o filho (Abrigo de familia) }\end{array}$ & 2 & 0,12 & 0 & 2 \\
\hline $\begin{array}{l}\text { Exploração sexual para fins de prostituição } \\
\text { infantojuvenil }\end{array}$ & 1 & 0,06 & 1 & 0 \\
\hline Total & 1.706 & 100,00 & 771 & 935 \\
\hline
\end{tabular}

visível e preocupante, que seria o uso desenfreado do conceito de negligência para justificar os acolhimentos apontados nos dados acima. Já a outra questão, algo implícito e de certa forma camuflado para todos nós, é: será que o conceito de negligência não está sendo utilizado equivocadamente, e assim, substituindo a pobreza para motivar esses acolhimentos como foi praticado no Código de Menores?

Segundo dados do Disque 100 em 2014, das denúncias feitas ao serviço, $74,26 \%$ foram denegligência, já em 2015 o número correspondeu a $76,35 \%$ do total de recebimentos (gráfico 1). Cabe ressaltar que o serviço não é responsável por averiguar a veracidade da denúncia, e sim, apenas colher informações e repassar aos órgãos devidos para a averiguação da mesma.

\section{Judicialização da vida}

O modo de organização centrado na ordem jurídica onde imperam as decisões do juiz é entendido por judicialização da vida, fixando relações de poder através da lógica punitiva, atravessando as produções subjetivas para estabelecerem padrões de comportamento 


\section{Gráfico 1}

CRIANÇAS E ADOLESCENTES (comparativo 10 semestre) - 2014/2015

Tipo de Violação - Crianças e Adolescentes (mais recorrentes)

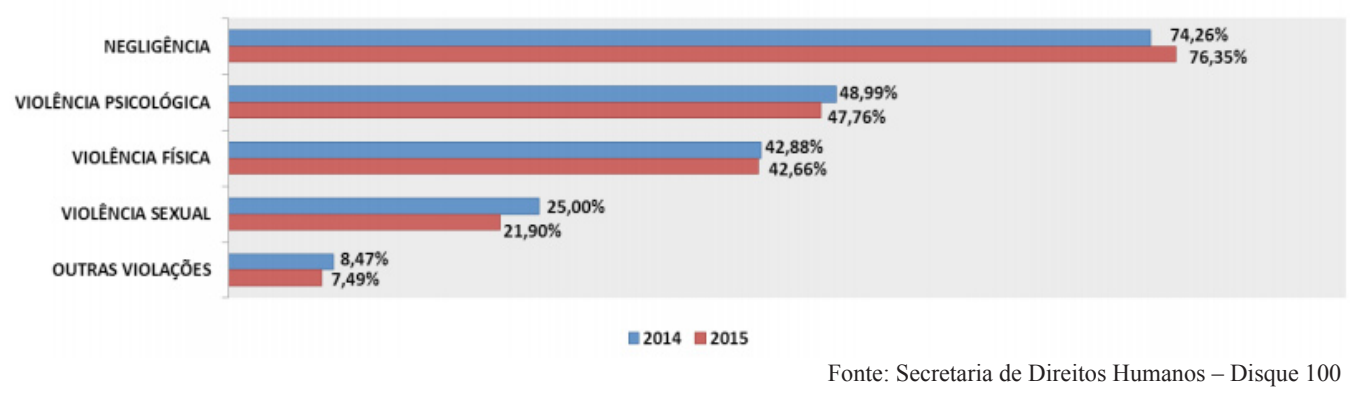

social e de conduta. A mesma lógica punitiva que vem sendo utilizada no sentido de "prevenir" e "corrigir" os "comportamentos desviantes" ao encontrar força neste modo de organização centrado na ordem jurídica.

Já por produção subjetiva ou de subjetividades denotamos aquilo que produz meu olhar, me faz entender, pensar, me constituir com ser único. São nossas experiências desde que nascemos e somos ensinados por diversos discursos que são muitas vezes introjetados sem mesmo passar por uma avaliação crítica antes.

"São, portanto, essas produções de subjetividades que constroem e definem as formas de pensar, perceber, sentir e agir no mundo, sendo forjadas pelos diferentes equipamentos sociais. Dentre eles, as práticas psicológicas", (COIMBRA ; LEITÃO, 2003, p. 9).

Essas produções interferem na conceitualização e no entendimento da negligência e da pobreza ao trazer "embarcado em suas costas" as ideias do higienismo, do código de menores pautando e subsidiando suas ações no modo de organização centrado na ordem jurídica, que é a judicialização da vida.

Para punir é preciso antes criminalizar, desqualificar as famílias que divergem dos modelos instituídos e classificar os pais/responsáveis de negligentes é uma forma de criminalização da pobreza, em uma associação imediata entre pobres e os fora da

Figura 1. Estrutura Judicializante da Negligência:

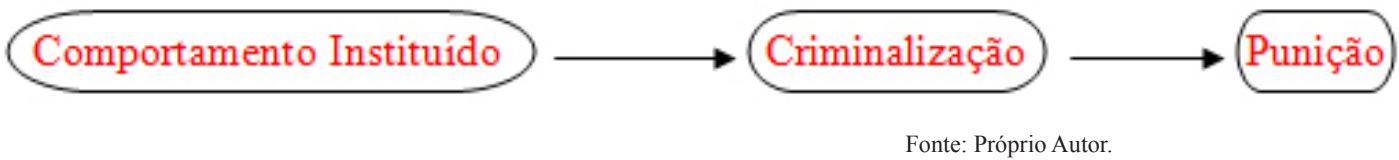

ordem (NASCIMENTO, 2011). O esquema acima sintetiza este fluxo como uma estrutura judicializante da negligência onde temos em primeiro lugar a constituição do comportamento considerado "normal e aceitável", sendo assim, seguido como padrão, posteriormente, a marginalização de todo o comportamento desviante e, por isso, criminalizado perante as leis e a sociedade e, por fim, a aplicação da lei e suas sanções como punição deste comportamento.

\section{Problematização sobre o acolhimento institucional}

Buscamos compreender, segundo o filósofo e teórico social francês Michel Foucault, como surgiram os domínios de saber que pautam as decisões jurídicas e estabelecem relações de poder que atravessam os contextos de famílias que vivenciam a experiência de um acolhimento institucional para com seus filhos. Outro questionamento que nos cerca, é o que faz com que o discurso de uma pessoa seja considerado determinante sobre a vida de outros seres humanos subjugados inferiores e passíveis de pena. $\mathrm{O}$ autor aborda em algumas de suas obras como: A Ordem do Discurso (FOUCAULT, 1996) e A Verdade e as Formas Jurídicas (FOUCAULT, 2002), as relações entre e conhecimento e como estes são utilizados como forma de controle social através das instituições sociais e dos discursos que produzem empoderamentos de classes superiores sobre as demais classes.

Foucault (2002) em "A verdade e as Formas 
Jurídicas" questiona como se puderam formar domínios de saber a partir de práticas sociais? Busca, a partir, destas práticas sociais, entender a verdade que forma domínios de saber que irão servir de base para o surgimento de novos objetos, conceitos, novas técnicas e novos modelos de sujeito. Apontando as práticas judiciárias como umas das mais importantes no engendramento de novas subjetividades. Desta forma, o conhecimento do Direito Penal atuaria como o lugar, ou um dos lugares, onde a verdade se forma e defini suas regras, suas leis que irão demarcar o limite do perigoso e do nocivo, do normal e do anormal, de algo que se considera aceitável dentro de uma sociedade e o que deve ser excluído e expulso.

A partir do discurso saber-científico a regra é estabelecida, e com ela, surgem as práticas regulares e as relações de poder que irão delimitar tipos de subjetividades, traçando também, a reparação que o indivíduo desviante deve realizar após o julgamento de seus erros, como forma punitiva e corretiva.

Como instrumentalismo da lógica punitiva surge o que denominamos de inquérito que se apresenta como "forma de pesquisa da verdade no interior da ordem jurídica" (FOUCAULT, 2002, p. 12). Tal pesquisa pela verdade teria por objetivo encontrar o autor, o momento e as condições que o levaram a executar tal ato com base na testemunha em que se procurava saber o que aconteceu. Posterior ao inquérito, temos a técnica do exame, da vigilância como forma de controle político e social do sistema econômico capitalista vigente na época através da "vigilância permanente sobre os indivíduos por alguém que exerce sobre eles um poder" (FOUCAULT, 2002, p. 87-88). No exame, não mais se busca determinar se algo aconteceu ou não, mas, quer determinar se este indivíduo esta se conduzindo ou não como se deve, como se estabelece a regra. Não se existe uma materialidade contundente do delito cometido, mas, a prevenção do comportamento desviante.

Assim, surge o conceito de periculosidade, onde o controle precisa ser exercido não apenas sobre o crime já cometido, mas sim, levando em consideração a possibilidade de realização do mesmo. Estipula-se o que poderiam e o que seriam capazes de fazer e consideram os indivíduos, a partir, de suas virtualidades e de seus comportamentos (FOUCAULT, 2002, p. 85).

A preocupação com a correção das virtualidades possivelmente apresentadas por determinados indivíduos, passa a tomar centralidade na teoria penal. Para se obter maior efetivação de seus resultados, ela se capilariza e se difunde, deixando de ser unicamente do Poder Judiciário e, passando então, ao Poder Executivo e Legislativo e, criando uma "rede de instituições de vigilância e coerção" (FOUCAULT, 2002, p. 86), como a escola, hospitais psiquiátricos, asilos, entre outros. Neste momento, outros saberes são agregados, como os conhecimentos psicológicos, médicos e pedagógicos.
A sociedade disciplinar denominada por Foucault surge em contrapartida às sociedades penais, após a implantação deste sistema de controle que agora está muito mais difundido e ampliado através de instituições e diversos conhecimentos científicos que propagam o discurso da periculosidade vinculada às virtualidades de cada um. Foucault (2002) denomina que esta passa a ser a idade do controle social e da ortopedia social, onde até a arquitetura dos prédios, escolas, hospitais e fábricas deveriam se articular para facilitar e manter a execução e o domínio do poder. Porém, a sociedade disciplinar não se afasta totalmente das sociedades penais, antes se apropria de algumas metodologias como os sistemas de penalidade que eram adotados e, que passaram por uma série de modificações até chegar ao que hoje denominamos de prisão ou aprisionamento como a forma de expressão maior de poder, controle extremo do corpo e do comportamento. No aprisionamento refletimos sobre os acolhimentos institucionais que vem sendo executados com crianças e adolescentes como forma de prevenção de uma conduta que os colocaria em situação de risco e vulnerabilidade social.

Bordin (2014, p. 225) afirma em sua leitura sobre Foucault, que toda relação de poder constitui algum tipo de saber, mas este poder é constituído anteriormente por um saber que dá a ele esse status de poder. As relações de poder se dão a partir do discurso, onde eles estão relacionados produzindo novos saberes e novos poderes sob aqueles indivíduos que se sujeitam a eles. Esse sujeitar-se não ocorre de forma incisiva e forçada, mas, de forma sutil, leve e envolvente, de maneira que nós $\mathrm{o}$ aderimos forjando nossa subjetividade. Para o autor, o poder está em todas as relações através de diversos discursos, como nas relações de pais e filhos, alunos e mestres, empregado e empregador etc. O poder é uma verdade que se estabelece através do discurso criando aqueles indivíduos que o legitimam e aqueles que são subjugados a ele e podemos perceber sua atuação através dos comportamentos, das linguagens e dos valores morais dentro de uma sociedade.

Foucault (1996, p. 10) aborda o conceito de discurso como um conjunto de construções verbais de frases e produções de signos que irão conferir modalidades de existências através de práticas discursivas. É nos discurso que a política, a medicina e outros saberes exercem suas forças, através da interdição que demonstra o desejo e o poder que está por detrás deste.

As relações de poder estabelecem os padrões de comportamento, como falar, como agir, o que é aceitável ou não, sua maneira de se vestir, estabelecem a noção de saudável e patológico, verdade e mentira e tudo o que possa conduzir e direcionar.

Cada sociedade tem seu regime de verdade, sua "política geral" de verdade: isto é, os tipos de discurso que ela 
acolhe e faz funcionar como verdadeiros; os mecanismos e as instâncias que permitem distinguir os enunciados verdadeiros dos falsos, a maneira como se sanciona uns e outros; as técnicas e os procedimentos que são valorizados para a obtenção da verdade; o estatuto daqueles que têm o encargo de dizer o que funciona como verdadeiro (FOUCAULT, 1979, p.12 apud BORDIN, 2014, p. 225).

Coimbra e Leitão (2003, p. 8) apontam que a divisão social do trabalho oriunda do sistema capitalista, instituiu e naturalizou o campo do saber-poder como: "o lugar do conhecimento/reconhecimento, da verdade, dos modelos, da autoridade, do discernimento, da legitimidade e adequação de certos modos de ser". Em contrapartida o campo do não saber como: "o da falta, caracterizado como território da exclusão, visto ser desqualificado, condenado, segregado, danoso e perigoso para a sociedade, que necessita ser acompanhado, tutelado, monitorado e controlado".

No cenário do capitalismo surgem os médicos higienistas e sanitaristas para tentar resolver os problemas de surtos epidêmicos de algumas doenças como febre amarela, varíola e tuberculose que se espalhavam entre a população. Este movimento denominado de higienismo tinha como linha de pensamento a higienização de espaços urbanos e defendiam a necessidade de estabilização de padrões sociais e de comportamento em nome da saúde e do bem de todos. Estes realizavam estudos nos espaços urbanos onde se crescia uma população necessitada de trabalho, orientação, educação, entre outros aspectos. Com os resultados, adotaram estratégias de controle sanitarista e condutas higiênicas nos espaços públicos e privados, que determinavam o zelo com o vestuário, a higiene pessoal, a preservação dos espaços íntimos e sociais e o comportamento social de cada indivíduo. $\mathrm{O}$ objetivo não era apenas o de preservar, promover saúde e qualidade de vida para os operários das indústrias ou a população em geral, e sim, preservar a mão de obra trabalhadora e produtiva que produzia a riqueza de uma classe abastada e que traziam prejuízo com os frequentes afastamentos do trabalho por motivos de saúde, além de eliminar, higienizar as ruas e com isso retirar aqueles que lá viviam (GÓIS JUNIOR; LOVISOLO, 2003).

Não se pode afirmar que o movimento higienista teve seu fim. Muitas de suas ideias e práticas estão presentes na sociedade em que vivemos, ao descrever normas e padrões de comportamento social para os espaços públicos e privados que foram instituídas pelo saber da Medicina e das Ciências da Saúde para atender a hegemonia do capitalismo industrial.

Tais práticas se caracterizaram como produtoras de subjetividades que visam os saberes e os sujeitos, formulando, assim, um determinado modo de ser humano, uma concepção de homem, sociedade, modelo de lar e família.

Para Foucault, as relações de poder de cada época é que determinam a busca de determinado conhecimento.
O capitalismo é um sistema econômico forte, e assim, obtinha seu status de poder. A ciência da saúde, ou seja, o saber médico se desenvolveu para manter o sistema vigente em funcionamento atendendo aos interesses de um determinado grupo. Segundo o autor, o discurso é o mecanismo utilizado para estabelecer as relações de poder entre os indivíduos e as classes sociais dando legalidade sob as ideias e doutrinas de quem as promovem.

[...] uma análise causal, em compensação, consistiria em procurar saber até que ponto as mudanças políticas, ou os processos econômicos, puderam determinar a consciência dos homens de ciência o horizonte e a direção de seu interesse, seu sistema de valores, sua maneira de perceber as coisas, o estilo de sua racionalidade: assim em época em que o capitalismo industrial começava a recensear suas necessidades de mão-de-obra, a doença tomou uma dimensão social: a manutenção da saúde, a cura, a assistência aos doentes pobres, a pesquisa das causas e dos focos patogênicos tornaram-se um encargo coletivo que o Estado devia, por um lado, assumir e, por outro, supervisionar (FOUCAULT, 2013, p. 199 apud BORDIN, 2014, p. 228).

Percebe-se que o saber não é algo consequente do conhecimento e nem mesmo inato, mas resultado de práticas de disciplina, de relações de poder que surgem em determinada época e com fins muito bem esclarecidos e objetivados.

[...] oscomportamentos sociais, as lutas, as relaçõesqueirãodar origem ao conhecimento. Ou seja, o poder em si só não existe, mas as relações de poder expostas em todos osâmbitose esferas é que originam o conhecimento (BORDIN, 2014, p. 226).

Sendo assim, vimos que os discursos científicos, médicos, higienista e sanitarista, foram se disseminando estabelecendo relações de poder da classe burguesa que detinha o poder capitalista. Foram estabelecendo também, padrões de comportamento social e familiar, o que veio a gerar legislações que visavam punir os comportamentos desviantes da ordem e do sistema vigente. É importante salientar que tais processos e estruturações citados acima, foram se constituindo de forma sutil e que demandam análises críticas já que incidem na produção das subjetividades.

\section{Considerações finais}

Pensando na cultura de institucionalização existente no Brasil, que ainda segue com alguns princípios e fundamentos similares do sistema menorista do Código de Menores mesmo após o surgimento do Estatuto da Criança e do Adolescente que trouxe a era da proteção integral; segundo os dados encontrados que mostram o alto índice de acolhimento de crianças e adolescentes que anteriormente se configurava 
por pobreza e na atualidade vem se configurando por negligência e, considerando, que a literatura nos aponta uma dificuldade de se estabelecer critérios para se fundamentar o uso deste conceito de forma menos discriminatória e segregativa, queremos questionar as produções subjetivas que se formam sobre a pobreza e as famílias atreladas à ela, bem como, tais acolhimentos que se pautam em modelos e práticas hegemônicas de uma classe social - burguesa capitalista - que determinou normas e padrões a serem seguidos, além, das devidas punições para quem não às seguissem e não se modelassem a elas.

Tais padrões vêm se mantendo nos discursos atuais de proteção de maneira sutil e implícito e servem como justificativas e embasamentos para ações judiciais. É nesta relação que surge o processo que denominamos de judicialização da vida, como uma prática capilarizada que visa a intervenção contínua deste poder superior.

É justamente esse processo que Foucault aborda em algumas de suas obras, ao falar das relações entre conhecimento e a utilização deste como forma de controle social através das instituições sociais e dos discursos que produzem empoderamentos de classes superiores sobre as demais classes.

A atuação do psicólogo nos diversos cenários em que é convocado a atuar como no Conselho Tutelar, nos equipamentos da Secretaria de Assistência Social e mesmo nas Varas da Infância e Juventude ou da Família, bem como, no Poder Judiciário, entre outros, ao ser convocado a elaborar laudos e pareceres no âmbito psicológico para embasar as decisões, deve ser a de trazer uma postura de análise e reflexão sobre esses conceitos previamente estabelecidos, as relações e os efeitos que eles produzem no indivíduo, na família e na sociedade em geral; buscando uma superação dos enfrentamentos familiares e sociais para se preservar e manter os vínculos afetivos que constituem essas famílias

\section{Referências}

ANDRADE, R. de O. ECA Comentado. artigo 2, livro 1 - tema: Direitos; 2016. Disponível em: http://fundacaotelefonica.org.br/promenino/trabalhoinfantil/promeninoecacomentario/eca-comentado-artigo-23livro-1-tema-direitos/. Acesso em: 16 Jan. 2018, 14:17:10

ARANTES, E. M. M. Pscicologia jurídica no Brasil. 3. ed. Rio de Janeiro: NAU, 2015 .

BORDIN, T. M. O saber e o poder: a contribuição de Michel Foucault. Saberes, Natal RN, v. 1, n. 10, nov. 2014, p. 225-235. Disponível em: https://periodicos.ufrn.br/saberes/ article/view/5088/4925. 27 Dez. 2017.

BRASIL. Código de Menores. Rio de Janeiro, 1927. Disponível em: http://www. planalto.gov.br/ccivil 03/decreto/1910-1929/D17943A.htm. Acesso: 09 Jan. 2018.

Estatuto da Criança e do Adolescente. Brasília, 1990. Disponível em: http:// www.planalto.gov.br/ccivil 03/leis/18069.htm. Acesso em: 10 Jan. 2018.

Secretaria de Direitos Humanos. Brasília, 2015. Disponível em: https://www. sdh.gov.br/disque-direitos-humanos/disque-direitos humanos. Acesso em: 27 Dez. 2017
COIMBRA, C.; LEITÃO, M. B. Das essências às multiplicidades: especialismo psi e produções de subjetividades. Psicologia \& Sociedade; 15 (2): p. 6-17; jul./dez.2003 Disponível: http://www.scielo.br/pdf/psoc/v15n2/a02v15n2.pdf. Acesso: 28 Dez. 2017.

FOUCAULT, M. A ordem do discurso. 3. ed. São Paulo: Edições Loyola, 1996.

. A verdade e as formas jurídicas. 3. ed. Eng. Paulo de Frontin, Rio de Janeiro: Nau editora / editora Trarepa Ltda., 2002.

GONÇALVES, H. S. Pscicologia jurídica no Brasil. 3. ed. Rio de Janeiro: NAU, 2015.

GÓIS JÚNIOR, E.; LOVISOLO, R. H. Descontinuidades e continuidades do movimento higienista no Brasil do século XX. Rev. Bras. Cienc. Esporte, Campinas, v. 25, n. 1, p. 41-54, set. 2003. Disponível em: http://www.oldarchive.rbceonline.org.br/index.php/ RBCE/article/download/172/181. Acesso: 28 Dez. 2017.

MINISTÉRIO PÚBLICO DO ESTADO DO RIO DE JANEIRO. $1^{\circ}$ Censo da População Infantojuvenil Acolhida no Estado do Rio de Janeiro (30/05/2008). Disponível em http://mca.mp.rj.gov.br/censos/1o-censo/. Acesso em: 09 Jan 2018.

. $20^{\circ}$ Censo da População Infanto-juvenil Acolhida no Estado do Rio de Janeiro (31/12/2017). Disponível em: http://mca.mp.rj.gov.br/20o-censo/. Acesso em: 09 Jan 2018

NASCIMENTO, M. L. Primeiro colóquio internacional Michel Foucault. Publicado no site do youtube 8 de Nov. 2011. Disponível em: https://www.youtube.com/ watch?v=RtfZ0MX5Y0Y\&t=292s. Acesso em: 21 Dez. 2017.

PHEBO, L.B.; OJEDA, E.S. M altrato de ninos y adolescentes: um a perspectiva internacional. Bol.Ofíc.Sanit.Panam. v. 12, n. 2, p. 123-137, 1996.

SHEINVAR, E. Idade e Proteção: fundamentos legais para a criminalização da criança, do adolescente e da família (pobres). Produção de subjetividade e estratégia de poder no campo da infância e da juventude. Rio de Janeiro/Niterói; p. 1-15; 2002. Disponível em: $<$ http://www.infancia-juventude.uerj.br>estela>. Acesso em: 28 Nov. 2017

SILVA, R. B. Linhas e Redes de Proteção à Infância e à Adolescência. Niterói, UFF, 2014 